\title{
Retraction Note to: Distribution and ecological impact of exotic woody plant species inside sacred groves of Northwestern Ethiopia
}

\section{Amare Bitew Mekonnen ${ }^{1}$}

Published online: 19 May 2021

(c) Springer Nature B.V. 2021

\section{Retraction to: Biodiversity and Conservation (2019) 28:2845-2859 https://doi.org/10.1007/s10531-019-01799-4}

The Editor-in-Chief has retracted this article (Mekonnen 2019) in light of evidence that the study was supported and conducted by a collaboration between Bahir Dar University and Colgate University; the memorandum of understanding signed by both universities indicates that Colgate University owns any data collected as part of the collaboration. Permission was not given by the data owners to publish these data. Additionally, Colgate University has expressed concerns that the data presented in the article are not correct.

Author Amare Bitew Mekonnen does not agree to the retraction of the article.

\section{Reference}

Mekonnen AB (2019) Distribution and ecological impact of exotic woody plant species inside sacred groves of Northwestern Ethiopia. Biodivers Conserv 28:2845-2859. https://doi.org/10.1007/ s10531-019-01799-4

Publisher's Note Springer Nature remains neutral with regard to jurisdictional claims in published maps and institutional affiliations.

The original article can be found online at https://doi.org/10.1007/s10531-019-01799-4.

Amare Bitew Mekonnen

amarebitew8@gmail.com

1 Department of Biology, College of Science, Bahir Dar University, P.O. Box 76, Bahir Dar, Ethiopia 